\title{
Da melancolia em Padre Antônio Vieira e Machado de Assis
}

\author{
Ana LúCia Liberato TetTAmanzy \\ Universidade Federal do Rio Grande do Sul
}

\begin{abstract}
RESUMO: A MELANCOLIA TRADUZ SINGULARIDADES HISTÓRICO-CULTURAIS DE PORTUGUESES E BRASILEIROS. EM SERMÕES DE VIEIRA, TRADUZ-SE POR UMA "ERRÂNCIA MENTAL E FÍSICA", SINAL DA NEGATIVIDADE DO ESPÍRITO PORTUGUÊS, PRESO A UM TEMPO ESTAGNADO E RESISTENTE AO BRILHO ALHEIO. EM CONTOS DE MACHADO DE ASSIS, PERSONAGENS INERTES E INVEJOSAS MANIFESTAM TANTO A INCONSTÂNCIA DA MORAL COMO A FIXIDEZ DO TEMPO MELANCÓLICO.
\end{abstract}

\begin{abstract}
MELANCHOLY TRANSLATES HISTORIC AND CULTURAL SINGULARITIES OF BOTH PORTUGUESE AND BRAZILIAN PEOPLE. IN SERMÕES BY VIEIRA, IT IS EXPRESSED BY MENTAL AND PHYSICAL DITHER, A SIGN OF THE NEGATIVITY IN THE PORTUGUESE SPIRIT, WHICH IS ATTACHED TO A STAGNATED TIME AND IS RESISTANT TO THE GLOW OF OTHERS. ON THE SHORT STORIES BY MACHADO DE ASSIS, INERT AND JEALOUS CHARACTERS SHOW MORAL INCONSTANCY, AS WELL AS THE FIXED MELANCHOLIC TIME.
\end{abstract}

PALAVRAS-CHAVE: ANTÔNIO VIEIRA - MACHADO DE ASSIS - MELANCOLIA KEY-WORDS: ANTÔNIO VIEIRA - MACHADO DE ASSIS - MELANCHOLY 
Nenbum homem é feliz até que morra. Sófocles - Édipo rei

melancolia tem rendido as mais diversas análises ao longo do tempo por distintas áreas do conhecimento, da medicina à religião, da psicanálise à filosofia. Em quase todas se convenciona tratar de moléstia do corpo ou do espírito, identificada, sobretudo, por uma permanente negatividade, que se traduz na dificuldade de atuação sobre o mundo e no desejo intenso de entendimento e contemplação do que existe. Em seu estudo sobre a obra de Benjamin, Susana Lages percebe, na figura do melancólico, que:

Ele sofre, na pele e na alma, de um mal-estar que provém da consciência demasiado aguçada de sua situação: apanhado entre um passado que o atrai com a (falsa) promessa da prazerosa satisfação total do desejo - que no limite confina com a morte - e um futuro que acena, como numa miragem, ao longe, com o objeto desejado. Seu maior e último desejo seria aquele de eliminar completamente as marcas do tempo, congelá-lo na eternidade de um presente que reunisse em si as duas outras dimensões temporais, sem o sofrimento decorrente do reconhecimento dessa impossibilidade e da realidade inquestionável da separação. (LAGES, 2002: 64)

Além de indivíduos, culturas e grupos humanos igualmente podem ser qualificados como portadores dessa particular consciência sobre o tempo. Nesse sentido, por diferentes razões, Portugal e Brasil tiveram, em determinadas circunstâncias, suas singularidades históricas e culturais traduzidas a partir da melancolia. Para dar conta dessa questão, são selecionados sermões do português Antônio Vieira e contos do brasileiro Machado de Assis com vistas ao exame das possibilidades de uma melancolia luso-brasileira, resultado dos encontros e desencontros de imperialismos de aquém e de além-mar, ou ainda de mundos coloniais e temas pós-coloniais postos em contato. 


\title{
Portugal entre a inveja e o messianismo ou das razões da melancolia em Vieira
}

\begin{abstract}
Contente-se cada um de crescer dentro de sua especie; contente-se cada um de crescer dentro da esphera do talento que Deus the deu, e logo conhecerão todos, que tem benção cada um no seu elemento. [...] Mas por todos os elementos se adoece de melancolia, por que nenhum se contenta com o crescer dentro de sua espécie: a andorinha quer subir a águia; a rêmora quer crescer a baleia; a formiga quer inchar a elephante.
\end{abstract}

Antônio Vieira - "Sermão da Terceira Dominga do Advento"

Em Portugal, de longa data manifestam-se discursos sobre a identidade lusíada como sendo sentimental, vinculada ao mar por fatalidade geográfica e vivida enquanto alternância entre um complexo de inferioridade e a fatalidade messiânica. Na compreensão da história, ressalta a proximidade com o mito e o mistério, refletida na perspectiva sebastianista ou nas mistificações da saudade. Esta, por sua vez, constitui sentimento defendido como próprio do português: paradoxal alegria de ser triste, desejo de recuperação do passado com vistas à sua repetição no futuro.

Se o século XIX é pautado, no plano das idéias, pelo discurso da decadência e pela consciência do atraso, o XX inicia com perspectivas regeneradoras como a do saudosismo de Teixeira de Pascoaes e Fernando Pessoa e a da utopia do império do Espírito Santo de Agostinho da Silva, ao lado do nacionalismo de ocasião que passa a ser suscitado pela ditadura salazarista, sobretudo à custa da manutenção do colonialismo nas terras de África. Contudo, pósRevolução dos Cravos, os esforços concentram-se em repensar criticamente o passado e colocar ordem na casa. Eduardo Lourenço estuda a melancolia, que, para ele, na modernidade, modula a relação com o tempo: "viagem através da eternidade perdida de nós próprios", "dor inexprimível do tempo que foge" ou, antes que a derrota às mãos do tempo, "última encenação de todo o nosso ser para aliviar o luto das nossas esperanças desfeitas, dos nossos anseios perdidos, dos nossos amores defuntos" (LOURENÇO, 1999: 98). 
Nesse contexto, vê a saudade como uma melancolia feliz, pessoal - dos portugueses - e universal, "sensação-sentimento de ardermos no tempo sem nele nos consumirmos", "consciência da temporalidade essencial da nossa existência, consciência carnal, por assim dizer, e não abstracta, acompanhada do sentimento subtil da sua irrealidade", por fim, "quando nada resta de nada, fica ainda o tudo desse nada. É o que vivemos como saudade". (LOURENÇO, 1999: 116-117).

Para um povo que viveu, concretamente, a distância representada pelo império além-mar e depois a difícil acomodação pela sua perda, tal relação para com o tempo parece mais do que natural.

Miguel Real, apesar da dicção diferente, chega a resultados semelhantes. Constata que "a figuração da cultura portuguesa se definiria substancialmente por uma espécie de vazio próprio apenas satisfeito ou preenchido pelo desejo que lhe está fora, sendo que este desejo do outro pode tomar corpo no desejo de regresso a formas do passado" (REAL, 1998: 172). Essa idéia é perspectivada de leituras como a de António José Saraiva, em que isso fora dito como "estar onde não se está"; a de Boaventura de Sousa Santos, no caráter de "cultura de fronteira", que vivenciou e vivencia ser o outro; a de Eduardo Lourenço, na "hiperidentidade irrealista" do português ou, ainda, as teses da vocação universalista ou cosmopolita de nomes como Jaime Cortesão, Agostinho da Silva e Fernando Pessoa. Segundo o autor, a adesão à Europa inspira incertezas a respeito de ser esse o único destino histórico de Portugal. Nos dias de hoje, aponta para uma discutível imitação - pela elite - de hábitos de consumo dos europeus e, simultaneamente, para a incúria pelo patrimônio cultural português, que, se não deve ser idealizado, é importante para o respeito que o país pretende alcançar para além de índices positivos de sucesso econômico imediato. Nesse sentido, avalia algo sobre a mentalidade portuguesa muito útil para este estudo. A antiga propalada inclinação para a emotividade, aliada ao descaso para com um pensamento científico e tecnológico, manifesta-se como uma "errância mental e física", que se concretiza na linguagem cotidiana:

Através de uma relação de rodeios, de subentendidos, de uma espécie de incapacidade de dizermos abertamente o que pensamos [...] É esta obliqüidade na assunção do fazer e do agir, que são sempre indirectos, que avançam em espirais, rodeando o alvo-objectivo, sem nunca o referir expressamente como motivação última, que nos permite dizer que "fazemos" e depois "não faze- 
mos", que "estamos" e depois "não estamos", e que, elevado a um nível de consciência, materializa-se no arrastamento das situações, acabando estas por resolver-se pela força do tempo. (REAL, 1998: 186)

Sentimento de inadequação profunda com o tempo, essa errância mental e física percorre como uma espécie de sintoma alguns escritos seiscentistas de Padre Antônio Vieira. Pode traduzir-se tanto em defeitos que infestam o indivíduo, como em vícios que minam os governos e as nações. No sermão "Primeira Oitava da Páscoa" (1647), atenta para a dificuldade de fazer os homens felizes: "Porque é muito mais dificultoso o contentar que o remir" (VIEIRA, 2001: 101).

Nesse sentido, o conselho que dá ao Príncipe para que examine de onde vêm as lágrimas dos Vassalos revela-se particularmente apropriado à confirmação da perspectiva melancólica: "Se têm causa, ponha-lhe remédio, se não têm causa, não lhe dêem cuidado" (VIEIRA, 2001: 104), de modo que reputa como inútil tentar aplacar o que não tem causa - no caso, a enorme inveja que resulta em melancolia. Como se sabe, na arquitetura discursiva de Vieira, é marcante o recurso de, para tratar de seu tempo, trazer a história sagrada. É assim que compara os que descrêem da ressurreição de Cristo com os portugueses enriquecidos com as conquistas além-mar: os judeus esperavam um homem, e veio o filho de Deus, o que não lhes saciou a espera, assim como "Quantos há hoje em Portugal que têm mais do que nunca esperaram, e no cabo ainda estão descontentes?", de modo que, mais uma vez, explica esse descontentamento como uma sem-razão que não tem justificativa, "Irracional afeto é a esperança descontente, vilíssimo afeto é” (VIEIRA, 2001: 112).

Nessa mesma direção, "Santo Antônio" (1671?), sermão proferido em Roma na Igreja dos Portugueses, reitera a inveja como motor das ações lusitanas. Santo Antônio, por ser português e por ser pregador, estava destinado a sair de Portugal, terra que não suporta viver com homens de grande valor nem acredita neles. Vieira usa de várias metáforas para explicar quanto incomoda aos portugueses ver luzir os grandes: "Ali se afogam os raios, ali se sepultam os resplendores, ali desaparece e perece toda aquela pompa de luzes" (VIEIRA, 2001: 428). Se nesse fragmento a alusão à inveja é direta, no que segue, própria da construção alegórica da época, tem-se a imagem da mãe madrasta, da terra que gera e devora os frutos: "Que importa que como mãe 
seja tão felizmente fecunda nos partos, que os gere de tão eminente estatura, se, como Dragão peçonhento, com raiva de os ver tão grandes, os morde, os rói, os abocanha, os atassalha, e não descansa até os engolir, e devorar de todo: Terra devorat habitatores suos?" (VIEIRA, 2001: 430). Essa imagem remete a Crono, definido por Karl Kerényi (2000), a partir de uma perspectiva mitológica, como "pensador tortuoso". ${ }^{1} \mathrm{O}$ deus devora os próprios filhos e, por essa razão, veio a ser cultuado como melancólico, na emblemática resistência à passagem do tempo, materializada nos descendentes por ele aniquilados.

Mais adiante, Vieira explica por que razão só alguns podem ver a luz: "Veio a luz ao mundo, e os homens (quem tal havia de imaginar?) amaram mais as trevas que a luz. Quantas vezes se vê isto no mundo, e eu o tenho visto? Ver os que luzem, é para rir; e ver os que não luzem, para chorar" (VIEIRA, 2001: 434). Dada essa incapacidade de diferenciar a mediocridade da grandeza, Lisboa haveria de expulsar seus mais brilhantes filhos: "Que filhos tão grandes e tão ilustres terias, se assim como nascem de ti, não nascera juntamente de ti, e com eles, a inveja que os afoga no mesmo nascimento e não os deixa luzir, nem crescer?" (VIEIRA, 2001: 437). Ainda sobre o veneno corrosivo da inveja, explica que só depois da morte o invejoso tolera admirar a luz alheia: "Enquanto as luzes são vivas, cada reflexo delas é um raio, que cega os olhos da inveja: porém, depois que elas se apagaram, e muito mais se metem largos anos em meio, então abre a inveja, como ave noturna, os olhos; então vê o que não podia ver" (VIEIRA, 2001: 442).

Esse tipo de reflexão justifica-se facilmente se pensarmos que o jesuíta sentiu na pele o peso da perseguição em seu país (mas também fora dele, a bem da verdade), causada pela dificuldade de entendimento sobre sua complexa perspectiva, que defendia com virulência tanto as paixões de sua alma como as convicções de seu espírito. Atacava os privilégios e a tacanhez das elites portuguesas, defendia os índios do Maranhão perante os colonos lusitanos, desdenhava o medo da

1 Como explica Kerényi (2000), a deusa Géia, a Terra, estava inconformada com o "trabalho perverso" do marido, Urano, o deus do céu, que após o nascimento dos filhos escondia-os sob a terra para nunca verem a luz do sol. A pedido da mãe, Crono, que era o filho mais novo, mutila o pai, decepando seu membro viril. Crono passa a reinar no lugar do pai e desposa Réia, uma de suas irmãs. No entanto, como os pais Urano e Géia haviam vaticinado que Crono seria deposto por um filho poderoso, ele devorava seus filhos assim que deixavam o ventre da mãe. Auxiliada pelos pais, Réia consegue que o filho Zeus sobreviva à fúria paterna. Chegado o momento, Zeus luta com o pai e faz com que devolva de suas entranhas os filhos engolidos. Liberta também os irmãos de seu pai, que Urano mantinha agrilhoados. Apesar disso, o reinado de Crono coincide com um período feliz da história do mundo, que é a Idade de Ouro. 
morte e a hipocrisia em platéias cultas da Europa. Causava não só inveja, mas ira. Por outro lado, tem-se os textos, heréticos ou não, em que aborda sua crença na predestinação dos portugueses. É o caso do "Sermão de Santo Antônio" (1670), de mesmo nome e também pregado em Roma, em que defende o caráter excepcional da missão apostólica dos portugueses pelo mundo: "Glória singular do reino de Portugal, que só ele entre todos os do mundo, foi fundado e instituído por Deus" (VIEIRA, 2000: 281). Por essa razão, deviam expandir a fé - quer dizer, a luz: "Lusitanos, para que trouxessem no nome a luz; mundanos para que trouxessem no nome o mundo; porque Deus os havia de escolher para luz do mundo" (VIEIRA, 2000: 282). Nesse sentido, o argumento vieiriano evolui na defesa de que Santo Antônio bem exemplifica o destino português de ser grande, porém, longe da terrinha: "O brasão de nascer Português era obrigação de morrer peregrino: com as armas nos obrigou Cristo a peregrinar, e com a sepultura nos empenhou a morrer. [...] Para nascer, pouca terra; para morrer, toda a terra: para nascer, Portugal: para morrer, o mundo" (VIEIRA, 2000: 285). Se antes o português expulsava os que brilhavam demais, como um Crono invejoso da prole, aqui expulsa para executar o plano imperial divino, como luz do mundo.

Ora, o mesmo autor que ataca a mediocridade do espírito português, incapaz de conviver com o brilho, defende o caráter excepcional da pátria portuguesa. Como se vê, Vieira espelha a referida figuração da cultura portuguesa no "vazio próprio" de um tempo sem história, pairando ora no mito, ora na melancolia, característica privação do tempo em sua estaticidade e negatividade.

Essa contradição pode ser mais bem compreendida tendo em mente as concepções teológicas de Vieira. Paulo José Carvalho da Silva estuda a tristeza nos sermões de Vieira com base nos paradigmas da escolástica e da ciência. Acaba por identificar a missão apostólica do padre, que, em face do inevitável desterro do homem na terra - quem muito deseja, perde a liberdade de ser -, propõe a via mística como saída:

Segundo Vieira, com a Queda do Paraíso, constitui-se a condição de um ser, cuja estrutura natural é de uma ausência geradora de tristeza. Ausência que se perpetuaria historicamente na repetição desordenada do pecado, na errância humana pelos caminhos tortuosos da fé nas coisas corruptíveis. [...] A finalidade providencial da tristeza é, portanto, a de mover ao arrependimento e, assim, à conversão. (SILVA, 2000: 101) 
Nesse caso, manter-se preso à "corrupção" da materialidade significa ceder à errância da melancolia, só superada com a salvação. A coerência do sistema vieiriano evidencia-se na vinculação do plano político-terreno com a missão divina, na qual a monarquia portuguesa ocuparia papel central. Se para os homens a salvação consistia em abrir mão da vaidade terrena, aos impérios cabia coadunarem-se no plano universal salvacionista. Embora invejoso, o reino português ocupava o lugar do povo eleito para a missão universal. A tese de Vieira, em certa medida, ilustra a recorrência em Portugal das interpretações histórico-culturais que enfatizam a oscilação entre insignificância física e política e onipotência de matriz mítico-religiosa. Como resultante dessa ambivalência, nasce a melancolia - consciência, dolorosamente humana, acerca da fragilidade e inconstância de tudo.

\section{Preguiça e inveja os males do Brasil são ou da melancolia em Machado de Assis}

Dessa terra e desse estrume é que nasceu essa flor.

Machado de Assis

Não é recente, em se tratando da obra machadiana, o debate a respeito dos temas da ironia, por vezes travestida de pessimismo. Do ponto de vista da forma, a leitura do hibridismo dá uma idéia do quanto há de modernidade, confluência de tons e leitura a contrapelo dos gêneros na escrita do brasileiro. Do ponto de vista das idéias, uma síntese preciosa encontra-se na formulação do crítico Antonio Candido: "Sua técnica consiste essencialmente em sugerir as coisas mais tremendas da maneira mais cândida" (CANDIDO, 1995: 27). Nessa dicção problemática e problematizadora, identifica-se sua leitura da cultura brasileira, tisnada dos tons cinzentos da melancolia.

À época de Machado, não era estranha a sensação de apatia dos intelectuais em face da arbitrariedade dos fatos históricos: ambiente caótico, república tão frívola quanto bárbara, convulsões nativistas reprimidas, racismo e desigualdades persistentes no país que por mais tempo manteve a escravidão. Acusado de negar sua raça e de imitar o estilo europeu em sua escrita, o bruxo do 
Cosme Velho encontra uma forma discreta, porém penetrante, de dizer o seu lugar no mundo - o das margens, o da máscara socialmente aceita. Enigma simultaneamente pessoal e coletivo, a identidade é construída nas sombras. Para dar visibilidade a essa necessidade de disfarce na cultura brasileira, paradoxalmente alegre e triste, a ficção machadiana constrói uma galeria de figuras que sintetizam os sintomas da moléstia que afeta o corpo material e moral da nação. Personagens apáticos, que não conseguem agir, sobretudo não conseguem fazer escolhas, e personagens invejosos, que parasitam as ações e posses alheias, representam na ficção os sintomas das sucessivas "modernizações conservadoras" no Brasil, em que se muda algo para que fique como está. O repertório cientificista em voga no período oferece ao autor uma irônica chave de leitura para as mazelas morais e sociais. Utilizando-se do jargão da medicina higienista da época, Machado faz como que uma anatomia das instituições e dos grupos sociais e de suas práticas aberrantes. Trata-se de uma paralisia funcional, estranhamente familiar à errância mental e física dos lusitanos, expressa nas situações que se resolvem antes pelo desgaste do tempo que pelas ações.

Sobre os inertes, seleciona-se a jovem Clara, do conto "Trina e una", que não aparece nas obras organizadas por Machado. Foi publicado recentemente por John Gledson (1998, p. 46), que a ele dá destaque justamente por apresentar uma personagem "negativa". Vítima da inércia, sua patologia pode ser lida como um traço cultural. A jovem configura no corpo e no temperamento a fleuma do melancólico: observa, olha, esgarça o tempo e não consegue decidir, sua existência é tão tediosa quanto insignificante, pautada nas razões do consumo e do supérfluo, parasita de sua incapacidade de ação sobre o mundo. Encontra uma explicação na figura de Hamlet, assim descrito por Rouanet:

As hesitações de Hamlet são típicas, em geral, do comportamento do Príncipe. Ele hesita, porque está na fronteira de dois mundos, porque sua condição em si é ambivalente. Ele é criatura, sujeito à natureza, e soberano, cuja tarefa é subjugar a natureza. O verdadeiro nome desta hesitação é acedia, a sombria indolência da alma, traço mais geral da sintomatologia melancólica. (ROUANET, 1985: 30)

Clara, o exemplo mais acabado da atitude inercial, tem nos olhos a expressão melancólica das figuras principescas, instáveis quanto à sua posição su- 
perior. Enquanto despendia horas na loja de tecidos, "olha para fora, para as pedras da rua, não para as pessoas que passam" (ASSIS, 1998: 162), ilustrando a atitude entre distraída e concentrada do melancólico. Tais características são ressaltadas nos comentários do narrador, que especula que Clara olhe, talvez, por distração, a cabeça sem ânimo nem vida. Quando na rua, no espaço público da loja de rendas, examina as mercadorias "com vagar, quase digo com preguiça” (ASSIS, 1998: 163). Chama atenção a insistência, observada pelo narrador, com que a indolente personagem pousa os olhos cansados, "fixos como uma idéia de doido" (ASSIS, 1998: 164), sobre as pedras da rua, ditas tão frias e secas como a dama. O mesmo ocorre no espaço doméstico: "Margaridas pintadas em papel. Ao mesmo tempo que reparava nas pinturas, ia-se sentindo bem, espreguiçando-se moralmente, e mergulhando na atonia do espírito". (ASSIS, 1998: 166).

Para o indivíduo nascido sob o signo de Saturno, o tempo é o meio da repressão, da inadequação, da repetição, mero cumprimento. No tempo, somos apenas o que somos: o que sempre fomos. No espaço, podemos ser outra pessoa. [...] O espaço, ao contrário, é amplo, fértil de possibilidades, posições, intersecções, passagens, desvios, conversões, becos sem saída, ruas de mão única. $\mathrm{Na}$ realidade, demasiadas possibilidades. Como o temperamento saturnino é vagaroso, propenso à indecisão, às vezes precisamos abrir caminho de faca na mão. Às vezes acabamos virando a faca contra nós mesmos. (SONTAG, 1986: 91)

Anódina em suas decisões, sua vida concentrava-se em atos vazios, expressão, esta sim, eloqüente de seu caráter, tanto que acaba casando por ter distraidamente respondido "sim" a um insistente interlocutor: "Ela era um modelo acabado de inércia moral; e casou para acabar com a importunação do Matias. Casaria com o diabo, se fosse necessário” (ASSIS, 1998: 173). O "sim" que equivale a um "não" remete muito claramente à errância de tempo e espaço de que fala Miguel Real sobre a forma com que, na linguagem, manifesta-se a irresolução dos eventos para os portugueses.

O segundo exemplo, o invejoso Nicolau, do conto "Verba testamentária" (do volume de contos Papéis Avulsos), proporciona a caracterização mais evidente do melancólico. Nele sobressai a vinculação dos aspectos físicos com os correspondentes elementos do caráter. Destarte, tem-se um sujeito que é apre- 
sentado como possuidor de uma bizarra moléstia que lhe provoca reações físicas, tais como secreções estomacais, esgares fisionômicos e sufocações, quando das ocasiões em que sua patologia é estimulada, a saber, nos momentos em que é possuído pela inveja. À semelhança do preguiçoso, o olhar é sua marca: se são os olhos que se evadem na contemplação oca no caso dos vitimados pela preguiça, são eles também que acendem o veneno na admiração das virtudes alheias no caso do invejoso. Nessas ocasiões, a doença faz Nicolau agredir ou até destruir o objeto de seu desejo, inevitavelmente propriedade ou qualidade alheias. Outra decorrência do mal é a irrupção do furor, indicativo do comportamento do ser de exceção. Na hipótese do cunhado, Nicolau é "doente do baço", o que, de imediato, remete às tradicionais referências, na tradição sobre a melancolia, desse órgão como sede do sangue seco e frio, atributos dos humores próprios das vítimas de tal moléstia. ${ }^{2}$

Obrigado a conter-se, a engolir o impulso, padecia dobrado, fazia-se mais lívido, com reflexos de verde bronze; em certos casos, era compelido a voltar os olhos ou fechá-los, para não arrebentar, dizia ele. [...] nada fixo, nada metódico, teremos algumas das dolorosas conseqüências do fato mórbido, oculto e desconhecido. (ASSIS, 1994: 359-360)

A dor do vicioso em momento algum é escamoteada, em contraste com inúmeros casos de inveja dissimulados no convívio social, tal é a dificuldade usualmente enfrentada por seus possuidores em admiti-la. Pior ainda, com o tempo, a miséria de Nicolau faz com que os sintomas físicos tornem-se mais graves, ao passo que as atitudes sofisticam-se ao ponto de optar por viver cercado de pessoas e objetos medíocres a fim de evitar a aparição da patologia. A dualidade e a inconstância inerentes ao melancólico tornam o invejoso vítima de atitudes contraditórias - num dia, trata bem empregados e animais; no outro, repele-os com violência, de modo que termina sua existência "constantemente verde, irritado, olhos vesgos, padecendo consigo ainda muito mais do que fazia padecer aos outros" (ASSIS, 1994: 364). Embora,

2 Na perspectiva aristotélica, o problema da melancolia surge como sendo uma patologia corpórea, explicada a partir da bile negra, cujas reações orgânicas interferem nas condutas humanas. (Cf. ARISTÓTELES, 1998.) 
como o preguiçoso, também não atue sobre o mundo, secreta nas próprias entranhas o veneno de sua melancolia. Custa-lhe observar a bem-aventurança alheia, o corpo adoece da incapacidade de ser agente - ressente-se de olhar os sucessos alheios, mais do que de constatar a precariedade de sua existência pessoal. Age para dentro, corrosivamente, então adoece, morre.

Nascido sob o signo do Paraíso, projeção do imaginário fabuloso do medievo que chega ao renascimento, o Brasil cedo se revelaria aos olhos do colonizador como lugar do pecado, em que imperavam os vícios da luxúria, da gula e da preguiça. Tidos como melancólicos, os índios recusavam-se à submissão a uma lógica que os anulava; tomados pela saudade da África e pelo peso da opressão, os africanos rendiam-se ao banzo. Impossibilitados de ser por si mesmos, esses grupos foram destituídos de sua humanidade para se adaptarem à construção imaginária de um outro. Nos termos precisos de Octavio Paz:

$\mathrm{Na}$ Europa a realidade precedeu o nome. América, pelo contrário, começou por ser uma idéia. Vitória do nominalismo: o nome engendrou a realidade. O continente americano ainda não havia sido inteiramente descoberto e já fora batizado. O nome que nos deram nos condenou a ser um mundo novo. Terra de eleição do futuro: antes de ser, a América já sabia como iria ser. Mal se transplantou para nossas terras o imigrante europeu já perdia a sua realidade histórica: deixava de ter passado e convertia-se em um projétil do futuro. Durante mais de três séculos a palavra americano designou um homem que não se definia pelo que fizera e sim pelo que faria. Um ser que não tem passado, que não tem mais do que futuro, é um ser de pouca realidade. Americanos: homens de pouca realidade, homens de pouco peso. Nosso nome nos condenava a ser o projeto histórico de uma consciência alheia: a européia. (PAZ, 1996: 127)

A melancolia das personagens machadianas dá visibilidade à fragilidade na constituição de uma possível imagem do ser brasileiro. Inconstância, negatividade e tédio são atributos de uma população doentia, pervertida pelos impasses de uma história da qual não se sente parte. As mudanças, quando ocorrem, em pouco ou nada lhe afetam a existência. A representação literária mimetiza, assim, a pouca realidade daqueles nascidos como um projeto esvaziado de substância, condenados a um futuro que os anula no processo histórico.

Inquieto com o sentido da máxima dos navegadores europeus seiscentistas 
- Ultra aequinoxialem non peccari - de que não havia pecado ao sul do Equador, o economista Eduardo Gianetti formula uma singular explicação para a contradição intrínseca à formação cultural brasileira, cindida entre a civilização e o desregramento anárquico dos desejos.

A civilização entristece. Como alcançar os confortos e poderes da racionalidade cinza de Prometeu (o que pensa antes de agir), sem abrir mão dos gozos e delícias da impulsividade de Epimeteu (o que age antes de pensar)? É precisamente na intersecção dessas suas disposições, ouso crer, que reside o cerne da nossa utopia secreta de grandeza e realização. Apurar a forma sem perder o fogo: trópicos utópicos. (GIANETTI, 2000: 74)

Gianetti expressa a dificuldade em viver a complexidade cultural brasileira na não menos intrincada dinâmica contemporânea. Sendo impossível ignorar os condicionamentos históricos, físicos e simbólicos que expressam a sociedade e o pensamento brasileiros, o esforço de interpretação da cultura brasileira passa por dialogar com esse imaginário herdado do colonialismo e com suas inevitáveis heranças. O lugar que o Brasil possa ocupar no cenário atual implica a compreensão da contradição intrínseca que o constitui, para o bem e para o mal. A concordarmos com Machado de Assis, que reitera a representação da violência disfarçada nas instituições, nas classes e nos comportamentos inertes e invejosos, a patologia melancólica ainda serve como analogia para a compreensão de mecanismos da sociedade brasileira contemporânea. Em face do horror cotidiano e da corrupção disseminada, uma inexplicável apatia; em face da endêmica - porém disfarçada - guerra civil, os paliativos de uma frágil segurança privada, cada qual na sua cela particular, protegendo-se da besta fera que ronda ou fugindo para um paraíso qualquer - seja um condomínio isolado, seja uma Miami hiperbólica, seja uma Europa unificada.

Em certa passagem do Apocalipse, um dos livros mais surpreendentes e fantásticos da Bíblia, a ameaçadora ira do Deus dos hebreus dirige-se para o anjo da igreja de Laodicéia, acusado de tibieza em sua fé: "Conheço as tuas obras, sei que não és frio nem quente; oxalá foras frio ou quente. Mas, porque és morno, nem frio nem quente, começarei a vomitar-te de minha boca" (Apocalipse, cap. 3 , versículos 15-16). Invejosos e preguiçosos, que por diferentes razões são impelidos à inação, padecem do mesmo mal do anjo bíblico. Não se definem, 
não possuem um estado senão a indolência morna. Melancolia à portuguesa e melancolia à brasileira coincidem, assim, na busca de um tempo que ancore suas identidades e ao mesmo tempo libere-as da fixação.

Brasileiros à espera do futuro, portugueses ancorados no passado redivivo, ambos sob a prisão dos anéis de Saturno. Até quando?

\section{Referências Bibliográficas}

ARISTÓTELES. O homem de gênio e a melancolia: o problema XXX, I. Trad. do grego, apres. e notas Jackie Pigeaud. Trad. Alexei Bueno. Rio de Janeiro: Lacerda, 1998.

ASSIS, Joaquim Maria Machado de. Contos: uma antologia. Sel. e introd. de John Gledson. São Paulo: Companhia das Letras, 1998.

. Obras completas. Rio de Janeiro: Nova Aguilar, 1994. v. 2.

CANDIDO, Antonio. Esquema de Machado de Assis. In: Vários escritos. 3. ed. rev. e aumentada. São Paulo: Duas Cidades, 1995.

GIANETTI, Eduardo. Nada é tudo: ética, economia e brasilidade. Rio de Janeiro: Campus, 2000.

GLEDSON, John. Os contos de Machado de Assis: o machete e o violoncelo. In: ASSIS, Joaquim Maria Machado de. Contos: uma antologia. São Paulo: Companhia das Letras, 1998.

KERÉNYI, Karl. Os deuses gregos. Trad. Octavio Mendes Cajado. 3. ed. São Paulo: Cultrix, 1997.

LAGES, Susana Kampff. Walter Benjamin: tradução e melancolia. São Paulo: EDUSP, 2002.

LOURENÇO, Eduardo. Melancolia e saudade. In: Portugal como Destino seguido de Mitologia da Saudade. Lisboa: Gradiva, 1999.

PAZ, Octavio. Signos em rotação. Trad. Sebastião Uchoa Leite. 3. ed. São Paulo: Perspectiva, 1996.

REAL, Miguel. Portugal ser e representação. Miraflores: Difel, 1998.

ROUANET, Sergio Paulo. Apresentação. In: BENJAMIN, Walter. Obras escolbidas. Trad. Sergio Paulo Rouanet. São Paulo: Brasiliense, 1985.

SILVA, Paulo José Carvalho da. A tristeza na cultura luso-brasileira: os Sermões do padre Antonio Vieira. São Paulo: EDUC - FAPESP, 2000.

SONTAG, Susan. Sob o signo de Saturno. Trad. Albino Poli Jr. e Anna Maria Capovilla. Porto Alegre: L\&PM, 1986.

VIEIRA, António. Sermões. Org. e introd. de Alcir Pécora. São Paulo: Hedra, 2000. t. 1. . Sermões. Org.e introd. de Alcir Pécora. São Paulo: Hedra, 2001. t. 2. 